\title{
Thinking Spatially in the Science Classroom
}

\author{
Nora S. Newcombe ${ }^{1}$
}

\begin{abstract}
Much scientific thinking is spatial in nature, and even non-spatial information is often communicated using maps, diagrams, graphs, analogies and other forms of spatial communication. Students' spatial skills are correlated with their success in learning science, both concurrently and predictively. Given that spatial skills are malleable, can spatial thinking be used to improve science education? This article reviews two ways in which we might proceed. Strategy 1 is to enhance students' spatial skills early in life, or at least prior to instruction. Strategy 2 is to make more effective use of spatial teaching techniques that allow for spatial as well as verbal learning, even by students with weaker spatial skills. Recent evidence suggests optimism about both approaches.
\end{abstract}




\section{$\underline{\text { Introduction }}$}

An important aspect of many scientific discoveries stems from the spatial nature of the relevant data. Consider, as an example, the history of understanding infectious disease. Ignaz Semmelweis, a careful observer with a brilliant hunch, made a start by observing in the 1840 os that washing hands between examining obstetric patients reduced the incidence of puerperal fever. But why should washing help? One step towards a germ theory of disease was taken in the 1850s, when John Snow put his observations of cholera cases in London on a map in juxtaposition with the location of water pumps, showing clustering around the pump on Broad Street (see Figure 1, top panel, for two modern visualizations of the data). Visualizations continue to play a role in scientific work on infectious disease, as shown in research on the history of the HIV virus (Figure 1, bottom panel). In addition, scientific education often uses spatial displays to communicate key ideas. Continuing with the science of infectious disease as an example, in the 1860 s, Louis Pasteur conducted experiments on pasteurization, effectively shown in a modern diagram as often found in science textbooks (Figure 1, middle left). Also in the 186os, Robert Koch figured out how to grow bacteria on agar, using a microscope for visualization (an example of such a preparation is shown in Figure 1, middle right).
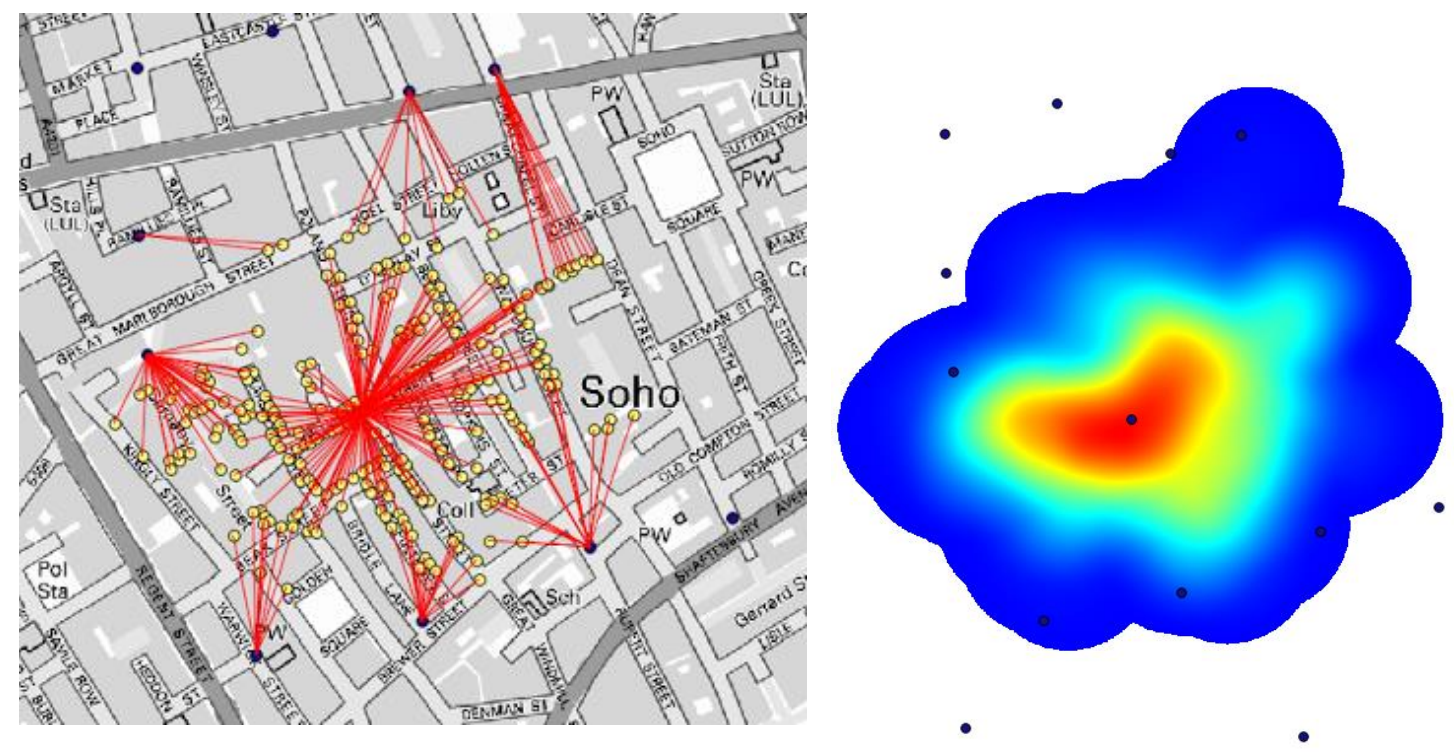

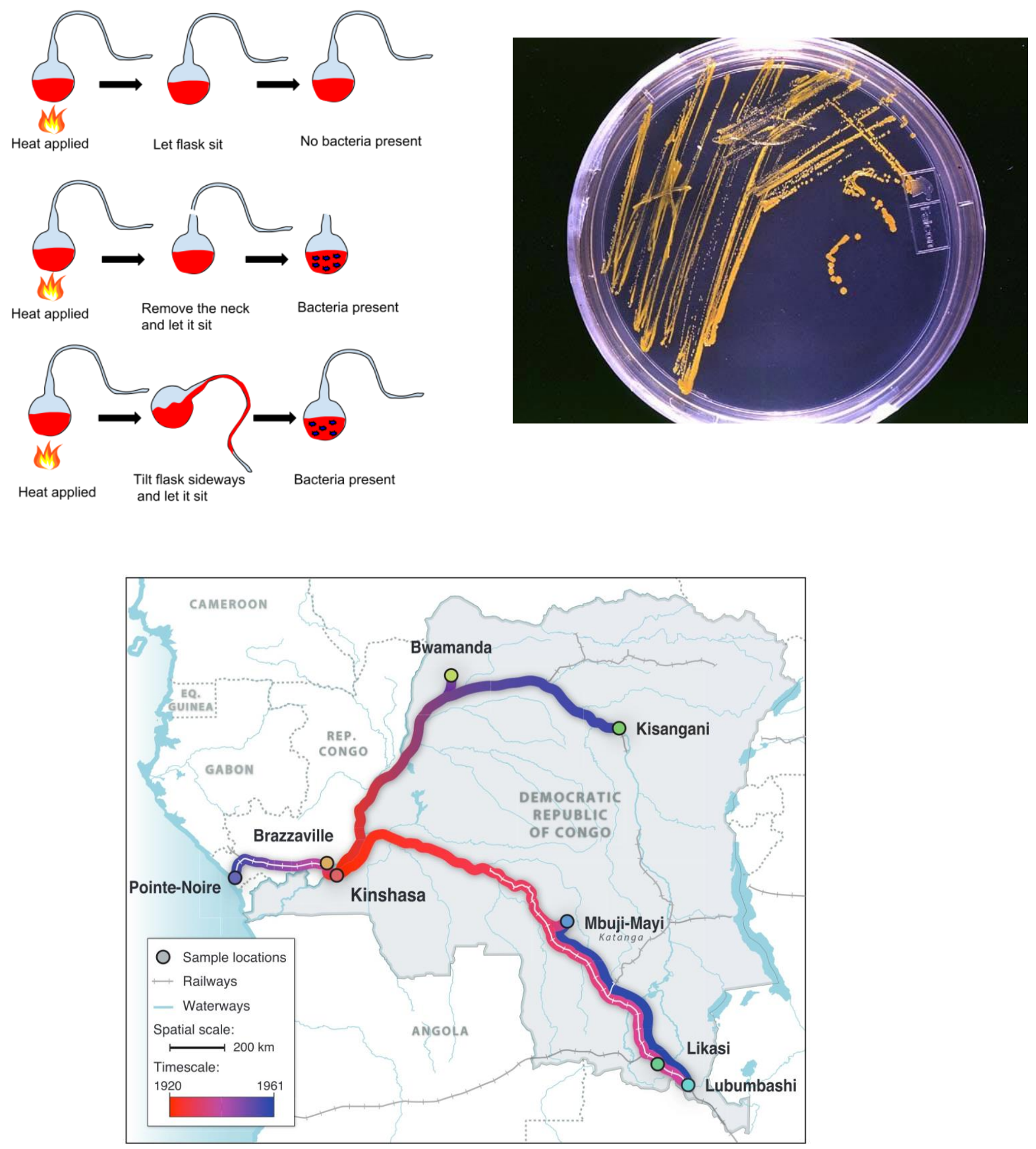

Figure 1: At top, two examples of modern visualization created from John Snow's cholera data http://qgissextante.blogspot.com/2012/10/analyzing-john-snows-choleradataset.html . In the middle panel, a diagram of Pasteur's experiment on the left and bacteria growing on agar on the right https://en.wikipedia.org/wiki/Petri dish\#/media/File:Agar plate with colonies.jpg At bottom, how the HIV virus spread and changed http://www.wired.com/2014/12/best-science-graphics-visualizations-2014/\#slide-12 
If scientific thinking is spatial, could spatial learning be harnessed to support more effective education in science and mathematics? There is in fact empirical support for the idea, based on various observations, e.g., the fact that students with higher spatial skills show better learning of topics such as kinematics (1) or a finding that gender differences in spatial ability mediate gender differences in science achievement in middle school (2). However, this general idea could play out in two different ways in the educational system. Strategy 1 might be to enhance students' spatial skills early in life, or at least prior to instruction, to enable better science learning. Strategy 2 might be for science educators to make more effective use of spatial teaching techniques that could allow for spatial as well as verbal learning, even by students with weaker spatial skills. That is, the focus would be on the curriculum, not on the learner. These possibilities are not mutually exclusive --both strategies might be important and effective. In that case, they could either be used together, or choices could be made between them on practical grounds, such as whether time and resources are available for pre-instruction spatial skills training. The purpose of this paper is to review recent evidence on these two strategies: (a) whether improving spatial skills affects science learning, and (b) how to spatialize the science curriculum.

\section{Strategy 1: Improving Spatial Skills}

Strategy 1 would be a non-starter if people were born with some innatelydetermined fixed level of spatial ability, with some individuals destined to be spatial geniuses while others are doomed to a permanent spatial fog. Fortunately, this belief, though common, is a myth. Meta-analysis of a wide variety of spatial training studies shows that spatial skills can be improved, for both men and women, and for adults as well as children. Furthermore, these improvements seem to be durable and transferable (3). These findings give rise to the hope that right-shifting the distribution of spatial skill in a population would increase the pool of people qualified to become part of the science and technology workforce (3, 4; see Figure 2). Interest in the malleability of spatial skills is growing, and experimenters continue to design engaging programs for spatial training suited to various ages and different spatial skills (5).

Randomized control trials. Note, however, that Figure 2, while built from facts, is still a thought experiment. The hope embodied in the figure would be more directly supported by experimental trials in which students were randomized to spatial skills training versus an active control group, with STEM achievement as the outcome (6). There have so far been few such efforts but, in the past few years, there are at least three publications with some positive findings. First, highly-capable physics students got higher grades after spatial training than a control group, although the effects did not appear as students went on to take later courses (7). Second, using a regression discontinuity design, investigators observed a positive effect of spatial training on performance in calculus, for less-capable students (8). Third, although this study lacked an effective active control group, education majors playing either of two kinds of video games seemed to improve on math performance as well as on other cognitive skills (9). Further studies of this kind are in progress, so we can expect more news in the next few years. 


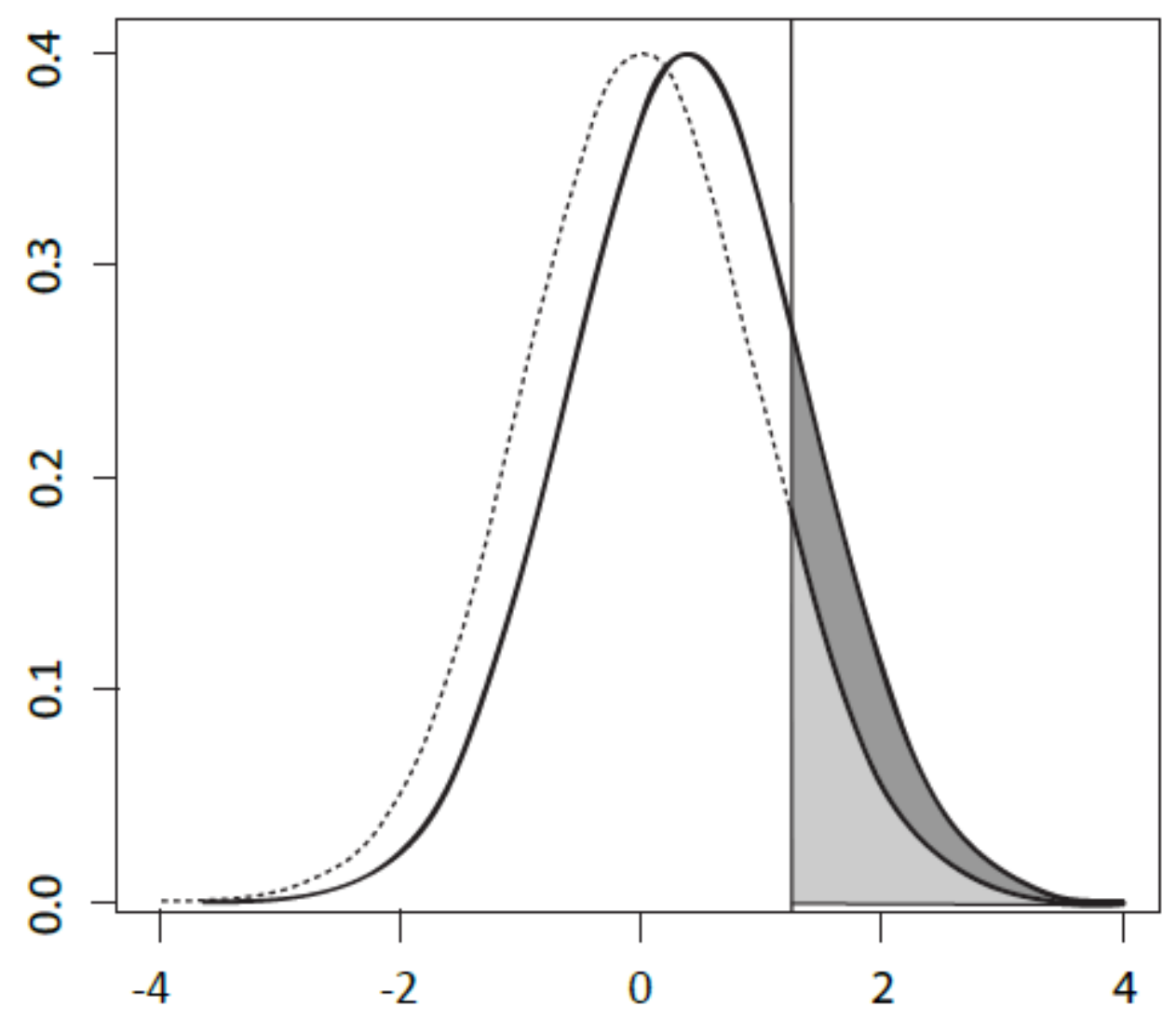

Figure 2: Spatial training could potentially double the number of students "spatially qualified" to become engineers. Based on Uttal et al. (2013).

Varieties of spatial skills. The three studies we have just examined used very different kinds of spatial training: practice on mental rotation and cross-sectioning (7), a one-credit course using a workbook designed to help engineering students with a variety of visualization skills and incorporating a good deal of drawing with feedback (8) and action-oriented video games of two different kinds, a first-person shooter game that requires a variety of spatial skills, and a low-stress game (9). Such heterogeneity is typical of the spatial training literature (3). However, there may be a variety of different spatial skills, each with different relevance to various scientific disciplines. Which should we train? There are hundreds of spatial tests, but how can they be grouped into kinds? One effort at a typology $(3,10)$ suggests that skills that focus on coding the structure of objects are different from skills involved in coding relations among objects in a wider world, and that intrinsic and extrinsic coding can each be static, or can involve active mental manipulation of the encoded information (see Figure 3). This typology, however, has yet to be thoroughly examined empirically. It may be too simple, because a close comparison of two skills (mental rotation and mental folding) that are both conceptually located in the bottom left of the figure as intrinsic-dynamic skills, reveals differences as well as similarities (11). Notably, mental rotation reliably shows a large sex difference whereas mental folding does not, but we do not know why they should be different in this regard. Even for mental rotation, a skill that has been the 
focus of considerable attention in cognitive science over the past decades, we are still uncovering new facts about its nature (12) and how it develops (13). Neural data might help to develop and differentiate this typology but only mental rotation has yet been studied extensively at the neural level (11).

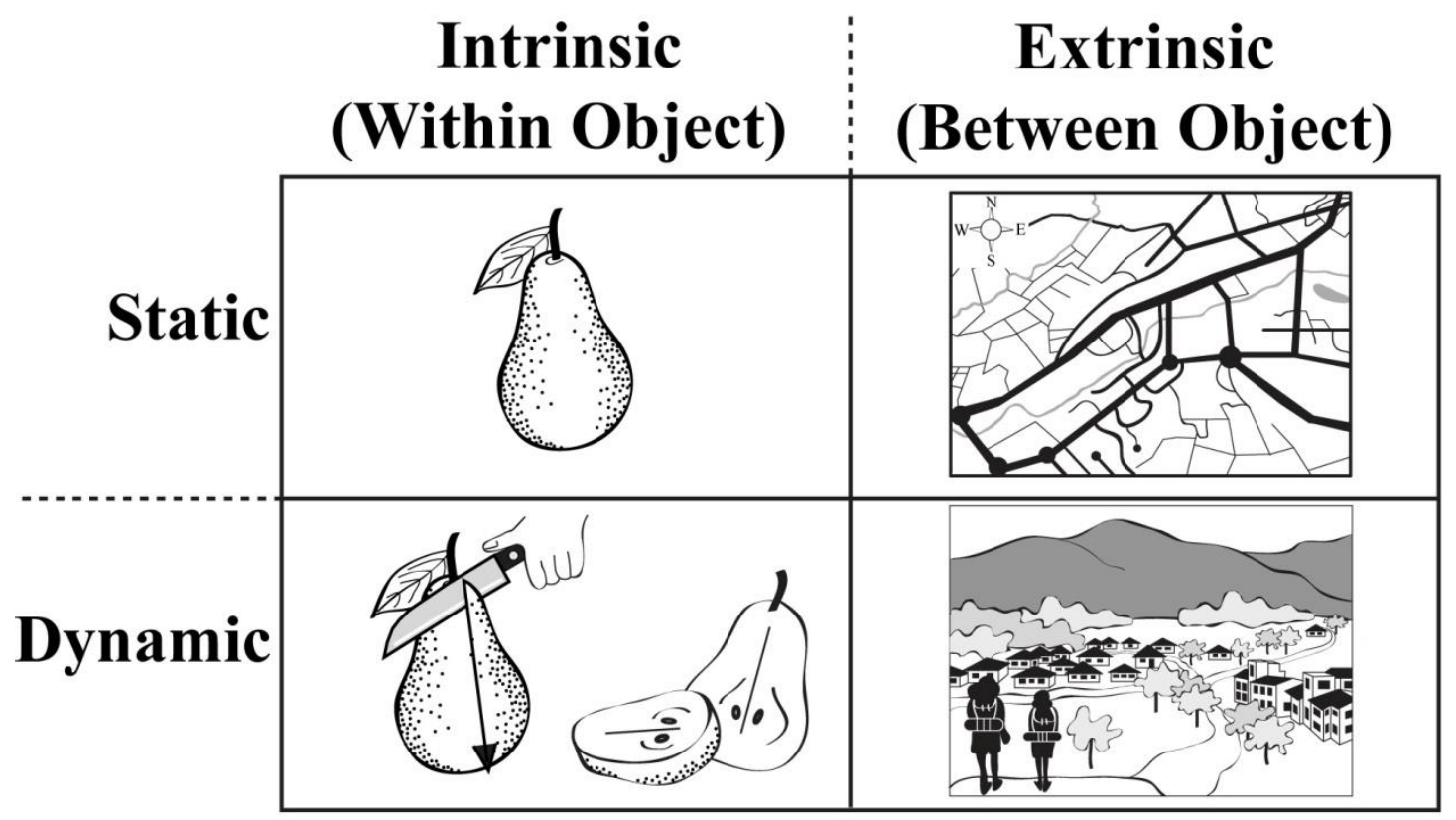

Figure 3: Typology of spatial skills, in which there is a distinction between thinking about objects and thinking about the environment, and also between static representations and dynamic transformations. The upper left cell includes tasks in which people represent the shape and structure of objects, and the lower left shows tasks in which that shape is changed, e.g., by cross-sectioning. The upper right cell shows tasks that require representing the relations among many objects in the wider world, and the lower right shows tasks that require imagining those relations changing, e.g., by changing vantage point.

Furthermore, even though there are hundreds of spatial tests, they have been devised over the past century almost entirely by psychometricians who were not interested in the particular kinds of spatial skills needed for success in specific scientific disciplines. One way to remedy the situation is to work closely with disciplinary experts to uncover neglected spatial skills, and to devise assessments for them. Interdisciplinary work between cognitive scientists and geoscientists indeed led to uncovering two such skills, bending and brittle transformation $(14,15)$. Many more may remain, and of course, fitting them into the typology proposed above will be a further challenge.

Assessing young children. One front on which there has recently been considerable progress is a basic practical matter. Many of the skills that have been wellstudied in adults have lacked techniques by which they could be examined in young children, especially important if we want to set children on a trajectory of strong spatial 
thinking. In the past few years, investigators have published new tests that tap mental rotation (16), perspective taking (17), paper folding (18), perception of diagrammatic representations (19), scaling (20) and the sophistication of 3-year-olds' ability to copy designs (21). Using these tools, we can demonstrate relations to developing scientific and mathematical skills $(21,22,23)$ and the importance in such development of activities such as construction play and working memory (24).

\section{Strategy 2: Spatializing the Science Curriculum}

Strategy 2 suggests that spatializing the science curriculum could improve science achievement for all learners. Such changes can occur at all instructional levels, beginning with playful science activities in preschool and extending into advanced science education at the graduate level. This strategy seems at odds with the common assumption that different students learn different ways, but there is encouraging evidence that appropriate modifications can aid weaker learners while not disadvantaging stronger learners, and maybe even helping them as well. In a recent study of organic chemistry classes (25), women showed best achievement levels when the professor used a combination of spatial and analytic strategies for understanding molecular structure, compared to spatial strategies alone, or analytic strategies alone. Men performed comparably across conditions. If spatial strategies and spatial thinking should be added to existing science curricula, there are several techniques that we have reason to believe would be helpful.

Maps and diagrams. As we saw in discussing the science of infectious disease, maps and diagrams play a ubiquitous role in science instruction and in scientific reasoning. Sadly, however, many instructors assume that these representations are basically pictorial, and that reading them does not require instruction. It turns out, however, that students need to be taught the reading of these representations, and that their science learning benefits (26). Further, they need to learn how to coordinate their reading of text and their reading of diagrams (27). One area of active investigation is when static representations (e.g., a diagram of a machine) are sufficient and when dynamic representations (e.g., a video or animation that shows the machine in action) add value, and for whom (28). We also need to specify better for early educators when and how to introduce these symbols $(29,30)$, although it is clear that their use should not be delayed, but rather start early but with careful sequencing and support.

Sketching. Sketching is the active creation of diagrams or maps by the learner. As a form of active learning, it is likely to be helpful, and its spatial nature is suited to science. However, this common belief needs further empirical assessment, although a recent study suggests support for the idea (31). Additionally, the nature of student sketches is diagnostic of their conceptual understanding (32), and sketching is thus likely to be helpful as a formative assessment in the classroom.

Action-to-abstraction. If active learning is helpful, then one might expect that literally active learning might be yet more helpful, i.e., physical experience of relevant scientific concepts. There is impressive cognitive and neural support for this idea, at least for concepts such as angular momentum that have obvious ways in which they can 
be felt (33). However, not all scientific concepts can be directly experienced, and even for those concepts that can be, science eventually requires abstraction for generality. These considerations give rise to the hypothesis that learning works best when arranged on an action-to-abstraction continuum (34). Gesture may be helpful in advancing the learner along this continuum, as it is both physical and abstract. It can express spatial relations at least as well as language, better in some ways because it can more easily show several relations close to simultaneously and also can indicate relations in an analogue fashion rather than making categorical cuts. Indeed, two recent studies support the efficacy of gesture, showing the involvement of the motor system in understanding others' gestures (35) and showing that gesture can work better than action, even action that is accompanied by words (36).

Analogy. Science instruction often uses analogy, as when the atom is compared to the solar system, or as when students are asked to understand the geologic time scale by analogy to the human life span. Analogies may be pictorial or verbal, but even when they are verbal, they have a spatial aspect in that they involve a structure mapping between elements in the two entities being compared. We are getting an increasingly good idea of when and how and why analogies work in the elementary classroom $(37,38)$, in children's museums (39) and for university students (40,41), as well as some idea of the neural underpinnings of analogical reasoning (38). Basic behavioral research continues on children (42) and adults (43).

\section{$\underline{\text { Conclusion }}$}

Research on the use of spatial thinking in improving science education is entering a new phase. It is now well established that spatial thinking is intimately interwoven with science learning, that spatial skills are predictively as well as concurrently predictive of science success, and that spatial skills are malleable. We now need to rigorously specify and evaluate how to use this information. We can improve students' spatial skills, but we need to use randomized control trials to evaluate effects on science achievement, as well as the durability of such effects and whether there is transfer to other domains. Improved specification of the domain of spatial skills would improve the incisiveness of such experiments and analyses, and research using brain imaging might aid such work. Expansion of inquiry into navigation skills and their relevance for scientific visualizations such as mapping would be welcome, especially given the probable plasticity in such skills and existing knowledge of their neural substrates (see for example, 44, 45). We can also improve how a variety of spatial tools are used in the science classroom, but those changes also need to be rigorously evaluated, and we need a sophisticated and deep understanding of how the tools work, at both the behavioral and the brain levels, to enable educators to adapt the tools for new contexts. 
Footnote

${ }^{1}$ Department of Psychology, 318 Weiss Hall, Temple University, Philadelphia PA 19122. newcombe@temple.edu

\section{Acknowledgments}

This work was supported by the National Science Foundation grant to the Spatial Intelligence and Learning Center SBE-1041707.

References and Recommended Reading

Papers of particular interest, published within the period of review, have been highlighted as:

*Of special interest

** Of outstanding interest

1. Kozhevnikov, M., Motes, M. A., \& Hegarty, M. (2007). Spatial visualization in physics problem solving. Cognitive Science, 31(4), 549-579.

2. *Ganley, C. M., Vasilyeva, M., \& Dulaney, A. (2014). Spatial ability mediates the gender difference in middle school students' science performance. Child Development, 85(4), 1419-1432. http://dx.doi.org/10.1111/cdev.12230

This research examined the role of spatial skills in gender differences in the science performance of 13-15 year olds. In a first study of over 100 children, mental rotation ability mediated gender differences in physical science and technology/engineering test scores. In a second study using a state population of eighth-grade students, and thus a very large sample, there were larger gender differences on test items that showed higher correlations with mental rotation.

3. Uttal, D. H., Meadow, N. G., Tipton, E., Hand, L. L., Alden, A. R., Warren, C., \& Newcombe, N. S. (2013). The malleability of spatial skills: A meta-analysis of training studies. Psychological Bulletin, 139(2), 352-402. http://dx.doi.org/10.1037/a0028446

4. Uttal, D.H., Miller, D.I. \& Newcombe, N.S. (2013). Exploring and enhancing spatial thinking: Links to STEM achievement? Current Directions in Psychological Science, 22, 367-373.

5. Taylor, H. A., \& Hutton, A. (2013). Think3d!: Training spatial thinking fundamental to STEM education. Cognition and Instruction, 31(4), 434-455. http://dx.doi.org/10.1080/07370008.2013.828727

6. Stieff, M., \& Uttal, D. (2015). How much can spatial training improve STEM achievement?. Educational Psychology Review, 1-9.

7. Miller, D. I., \& Halpern, D. F. (2013). Can spatial training improve long-term outcomes for gifted STEM undergraduates? Learning and Individual Differences, 26, 141-152. http://dx.doi.org/10.1016/j.lindif.2012.03.012 
8. Sorby, S., Casey, B., Veurink, N., \& Dulaney, A. (2013). The role of spatial training in improving spatial and calculus performance in engineering students. Learning and Individual Differences, 26, 20-29. http://dx.doi.org/10.1016/j.lindif.2013.03.010

9. Novak, E., \& Tassell, J. (2015). Using video game play to improve educationmajors' mathematical performance: An experimental study. Computers in Human Behavior, 53, 124-130.

10. Newcombe, N. S \& Shipley, T. F. (2015). Thinking about spatial thinking: New typology, new assessments. In J. S. Gero (ed.), Studying visual and spatial reasoning for design creativity (pp. 179-192). Springer.

11. Harris, J., Hirsh-Pasek, K. \& Newcombe, N.S. (2013). Understanding spatial transformations: Similarities and differences between mental rotation and mental folding. Cognitive Processing, 14, 105-115.

12. Xu, Y. Q. \& Franconeri S. L. (2015). The capacity for visual features in mental rotation. Psychological Science

13. Frick, A., Möhring, W., \& Newcombe, N. S. (2014). Development of mental transformation abilities. Trends in Cognitive Sciences, 18, 536-542.

14. Resnick, I., \& Shipley, T. F. (2013). Breaking new ground in the mind: An initial study of mental brittle transformation and mental rigid rotation in science experts. Cognitive Processing, 14(2), 143-152. http://dx.doi.org/10.1007/s10339013-0548-2

15. Atit, K., Shipley, T.F., \& Tikoff, B. (2013). Twisting space: Are rigid and non-rigid mental transformations separate spatial skills? Cognitive Processing: Spatial Learning and Reasoning Processes, 1-11.

16. Frick, A., Hansen, M. \& Newcombe, N.S. (2013). Development of mental rotation in 3- to 5-year-old children. Cognitive Development, 28, 386-399.

17. Frick, A., Möhring, W. \& Newcombe, N. S. (2014). Picturing perspectives: Development of perspective-taking abilities in 4- to 8-year-olds. Frontiers in Developmental Psychology. 5:386. DOI: 10.3389/fpsyg.2014.00386

18. Harris, J., Hirsh-Pasek, K. \& Newcombe, N.S. (2013). A new twist on studying the development of dynamic spatial transformations: Mental paper folding in young children. Mind, Brain and Education, 7, 49-55.

19. Frick, A. \& Newcombe, N.S. (2015). Young children's perception of diagrammatic representations. Spatial Cognition and Computation.

20.Möhring, W., Newcombe, N.S., \& Frick, A. (2014). Zooming in on spatial scaling: Preschool children and adults use mental transformations to scale spaces. Developmental Psychology, 5o, 1614-1619.

21. **Verdine, B.N., Golinkoff, R.M., Hirsh-Pasek, K., Newcombe, N.S., Filipowicz, A.T. \& Chang, A. (2014). Deconstructing building blocks: Preschoolers' spatial assembly performance relates to early mathematics skills. Child Development, 85 , 1062-1076.

This study developed a new test of 3-year-olds' spatial assembly skills using interlocking block constructions and evaluated its relation to early mathematical skills. Spatial skill independently predicted concurrent mathematical performance after taking account of other factors. Spatial assembly skill did not differ by 
gender, but lower SES children were already lagging behind higher SES children. Lower SES parents also reported using significantly fewer spatial words with their children.

22. Möhring, W., Newcombe, N. S. \& Frick, A. (2015). The relation between spatial thinking and proportional reasoning in preschoolers. Journal of Experimental Child Psychology, 132, 213-220. doi: 10.1016/j.jecp.2015.01.005

23. Möhring, W., Newcombe, N. S., Levine, S.C. \& Frick, A. (2015).Spatial proportional reasoning is associated with formal knowledge about fractions. Journal of Cognition and Development.

24. Nath, S., \& Szücs, D. (2014). Construction play and cognitive skills associated with the development of mathematical abilities in 7-year-old children. Learning and Instruction, 32, 73-80.

25. ${ }^{* *}$ Stieff, M., Dixon, B. L., Ryu, M., Kumi, B. C., \& Hegarty, M. (2014). Strategy training eliminates sex differences in spatial problem solving in a STEM domain. Journal of Educational Psychology, 106(2), 390-402. http://dx.doi.org/10.1037/a0034823

This study compared 3 interventions that trained mental imagery strategies, analytic problem-solving strategies, or both, in a college chemistry course. Training in the combined use of mental imagery and analytic strategies eliminated sex differences in achievement, whereas training either single strategy alone resulted men performing better.

26. Cromley, J.G., Perez, A.C., Fitzhugh, S., Tanaka, J., Newcombe, N., Shipley, T.F. \& Wills, T.W. (2013). Improving students' diagram comprehension with classroom instruction. Journal of Experimental Education, 81, 511-537.

27. Bergey, B. W., Cromley, J. G., \& Newcombe, N. S. (2015). Teaching high school biology students to coordinate text and diagrams: Relations with transfer, effort, and spatial skill. International Journal of Science Education. doi: 10.1080/09500693.2015.1082672

28. Sanchez, C. A. \& Wiley, J. (2014). The role of dynamic spatial ability in geoscience text comprehension. Learning and Instruction, 31, 33-45. http://dx.doi.org/10.1016/j.learninstruc.2013.12.007

29. Uttal, D.H., \& Yuan, L. (2014). Using symbols: Developmental perspectives. Wiley Interdisciplinary Reviews: Cognitive Science, 5(3), 295-304.

30.Uttal, D.H., \& Sheehan, K.J. (2014). The development of children's understanding of maps and models: A prospective cognition perspective. Journal of Cognitive Education and Psychology, 13(2), 188-200.

31. Sung, Y.-T., Shih, P.-C., \& Chang, K.-E. (2015). The effects of 3D-representation instruction on composite-solid surface-area learning for elementary school students. Instructional Science, 43(1), 115-145. http://dx.doi.org/10.1007/s11251014-9331-8

32.Jee, B.D., Gentner, D., Uttal, D.H., Sageman, B., Forbus, K.D., Manduca, C.A., Ormand, C.J., Shipley, T.F., \& Tikoff, B. (2014). Drawing on experience: How domain knowledge is reflected in sketches of scientific structures and processes. Research in Science Education. DOI: 10.1007/s11165-014-9405-2 
33. ${ }^{* *}$ Kontra, C., Lyons, D., Fischer, S., \& Beilock, S. L. (2015). Physical experience enhances science learning. Psychological

Science. DOI:10.1177/0956797615569355

Three laboratory experiments using brain imaging and one randomized field experiment explored the importance of physical experience in science learning, specifically with regard to whether understanding torque and angular momentum is aided by activation of sensorimotor brain systems. A brief exposure to forces associated with angular momentum, significantly improved quiz scores, and better performance was correlated with activation of sensorimotor brain regions. This finding specifies a mechanism underlying the value of physical experience in science education and supports classroom practices that integrate experience with the physical world into academic instruction.

34. Goldin-Meadow, S. (2014). How gesture works to change our minds. Trends in Neuroscience and Education (TiNE). doi: 10.1016/j.tine.2014.01.002

35. Ping, R., Beilock, S. L., \& Goldin-Meadow, S. (2014). Understanding gesture: Is the listener's motor system involved? Journal of Experimental Psychology: General, 143(1), 195-204. DOI: 10.1037/a0032246

36. Trofatter, C., Kontra, C., Beilock, S.L. \& Goldin-Meadow, S. (2014). Gesturing has a larger impact on problem-solving than action, even when action is accompanied by words. Language, Cognition \& Neuroscience. doi: 10.1080/23273798.2014.905692.

37. Richland, L. E., Simms, N. (2015), Analogy, higher order thinking, and education, WIREs: Cognitive Science. Volume 6(2), 177-192.

38. **Vendetti, M., Matlen, B., Richland, L., \& Bunge, S. (2015). Analogical reasoning in the classroom: Insights from cognitive science. Mind, Brain, and Education, $9(2), 100-106$,

The fundamental aim of science education is to teach so that students can apply knowledge from one context to another but this is notoriously difficult. Analogical reasoning involves the ability to extract similarities across contexts, but it is especially challenging in the context-rich and often high-pressure settings of classrooms. The authors suggest how to support analogical reasoning, with practical suggestions for classroom instruction. They include a review of the development and neurological underpinnings of analogical reasoning.

39. Gentner, D., Levine, S. C., Ping, R., Isaia, A., Dhillon, S., Bradley, C., \& Honke, G. (2015). Rapid learning in a children's museum via analogical comparison. Cognitive Science. Advance online publication. http://dx.doi.org/10.1111/cogs.12248

40.Jee, B. D., Uttal, D. H., Gentner, D., Manduca, C., Shipley, T. F., \& Sageman, B. (2013). Finding faults: Analogical comparison supports spatial concept learning in geoscience. Cognitive Processing, 14(2), 175-187. http://dx.doi.org/10.1007/s10339-013-0551-7 
41. Kurtz, K.J., \& Gentner, D. (2013). Detecting anomalous features in complex stimuli: The role of structured comparison. Journal of Experimental Psychology: Applied, 19(3), 219-232.

42. Shayan, S., Ozturk, O., Bowerman, M., \& Majid, A. (2014). Spatial metaphor in language can promote the development of cross-modal mappings in children. Developmental Science, 17(4), 636-643. http://dx.doi.org/10.1111/desc.12157

43. Goldwater, M.B., \& Gentner, D. (2015). On the acquisition of abstract knowledge: Structural alignment and explication in learning causal system categories. Cognition, 137, 137-153.

44. Maguire, E. A., Gadian, D. G., Johnsrude, I. S., Good, C. D., Ashburner, J., Frackowiak, R. S., \& Frith, C. D. (2000). Navigation-related structural change in the hippocampi of taxi drivers. Proceedings of the National Academy of Sciences, 97(8), 4398-4403.

45. Schinazi, V.R., Nardi, D., Newcombe, N.S., Shipley, T.F. \& Epstein, R.A. (2013). Hippocampal size predicts rapid learning of a cognitive map in humans.

Hippocampus, 23, 515-528. 